\title{
Analysis of direct power control AC-DC converter under unbalance voltage supply for steady-state and dynamic response
}

\author{
Nor Azizah Yusoff, Azziddin M. Razali, Kasrul Abdul Karim, Raja Nor Firdaus Kashfi Raja Othman, \\ Auzani Jidin, Nor Aishah Md Zuki, Nurfaezah Abdullah \\ Faculty of Electrical Engineering, Universiti Teknikal Malaysia Melaka (UTeM), Malaysia
}

\begin{tabular}{|c|c|}
\hline Article Info & ABSTRACT \\
\hline Article history: & \multirow{12}{*}{$\begin{array}{l}\text { This paper presents an analysis of Direct Power Control (DPC) technique for } \\
\text { the Three-Phase Pulse Width Modulation (PWM) AC-DC converter under } \\
\text { unbalanced supply condition. Unbalance condition will cause the presence of } \\
\text { unbalanced current and voltages thus produce the negative components on } \\
\text { the grid voltage as well as severe performance degradation of a grid } \\
\text { connected Voltage Source Inverter (VSI). The input structures for } \\
\text { conventional DPC has been modified with a three simpler sequence networks } \\
\text { instead of coupled by a detailed Three-Phase system method. The imbalance } \\
\text { voltage can be resolved by separating from the individual elements of voltage } \\
\text { and current into symmetrical components called Sequence Network. } \\
\text { Consequently, the input power relatively improved during unbalanced } \\
\text { condition almost } 70 \% \text { through the measurement of Total Harmonic } \\
\text { Distortion (THD) from the conventional Direct Power Control (DPC) in } \\
\text { individual elements which is higher compared to separate components. } \\
\text { Hence, several analyses are performed in order to analyze the steady state } \\
\text { and dynamic performance of the converter, particularly during the load and } \\
\text { DC voltage output reference variations. }\end{array}$} \\
\hline Received Nov 15, 2019 & \\
\hline Revised Dec 18, 2019 & \\
\hline Accepted Jan 31, 2020 & \\
\hline Keywords: & \\
\hline & \\
\hline & \\
\hline Direct power control & \\
\hline Unbalance voltage supply & \\
\hline Steady-state & \\
\hline Dynamic response & \\
\hline & \\
\hline
\end{tabular}

Copyright $@ 2020$ Institute of Advanced Engineering and Science. All rights reserved.

\section{Corresponding Author: \\ Azziddin Mohamad Razali, \\ Faculty of Electrical Engineering, Universiti Teknikal Malaysia Melaka (UTeM), 76100 Durian Tunggal, Malacca, Malaysia. \\ Email: azziddin@utem.edu.my}

\section{INTRODUCTION}

Power converter is necessary especially in AC and DC motor control circuits and acts as the link or the transforming stage between the power source and the power supply output [1]. There are several mains of converters based on the source of input voltage and the output voltage and these falls into four categories namely the AC-DC converter known as the rectifier, the DC-AC that named as inverter, the AC-AC converter or frequency changer, and lastly the DC-DC voltage or current converter. Each has its advantages and drawbacks, which determines the suitability for any specific application [2]. However, this research is approach for AC-DC converter for more specific and concern.

AC-DC converter plays an important role in many power electronics system. The vast application of this converter leads to the development of many control techniques. The example of control techniques covers hysteresis current control (HCC), voltage-oriented control (VOC) which similar to the Field Oriented Control (FOC) and Direct Power Control (DPC) which imitates the basic idea of Direct Torque Control (DTC). Each control technique has its own way of controlling the power converters as a result their aims to reduce the harmonics up to some limit [3].

However, these advanced features of PWM AC-DC converters are not fully achieve under the unbalanced three-phase input supply [4]. Thus, it indicates to harmful to all polyphase loads, especially 
three phase induction machines. Otherwise, unbalance system is produce excessive heat causing to equipment failures. Although various faults in the utility line tend to happend in a few second, this fault or disturbance at grid side may introduce significant unbalanced operating conditions [5]. Unbalanced three-phase input supply both in magnitude and in phase is quite common in power system, particularly in a weak AC system [6]. Usually, the non symmetrical transformer windings in a distribution can cause to unbalanced input supply conditions. Indirectly, it has been shown that unbalanced input voltages implies for the appearance of negative sequence in voltage and current thus leads to the oscillation of system variable [7]. Therefore, a PWM AC-DC converter under unbalanced operating conditions necessitates the use of filters to reduce the harmonics at the AC input side respectively. Thus, to achieve a lower disturbances and enhanced power quality by eliminate the harmonics under unbalanced voltage input supply, a few solutions have been approach in these cases. As a result, it is essential to have an adequate model to deal with the negative sequence input voltage as well as positive sequence input voltages.

Subsequently, this paper is mainly focussing on the Direct Power Control (DPC) strategy, which it based on the instantaneous of active and reactive power control loops [8, 9]. However, conventional approaches of DPC cannot be applied for generalized unbalanced operating conditions. In this paper, DPC is modified to manage power flow during unbalanced voltage supply so that sinusoidal balanced grid currents are obtained. With this new strategy, DPC overcomes the problems related to grid voltage imbalance and can accomplished new regulation laws. At the end of this paper, the converter performance will be evaluated under steady state and dynamic conditions. The converter's dynamic study is performed by evaluating the transient response during the magnitude variations of DC voltage reference and load resistance.

\section{BASIC STRUCTURE DIRECT POWER CONTROL}

The Direct Power Control (DPC) is based on the Direct Torque Control (DTC) concept in electrical machines. The intention for DPC is to control the instantaneous of active and reactive power control loops [10] as the same direction for DTC in controlling the torque and flux of induction machines. In this DPC scheme as shown in Figure 1, switching table plays a major part [11]. The input to the switching table will be the instantaneous error of the active power $d P$, reactive power $D q$ and the voltage vector position $\theta_{n}$ as shown in Table 1. This switching table enables the converter to select the appropriate of switching states.

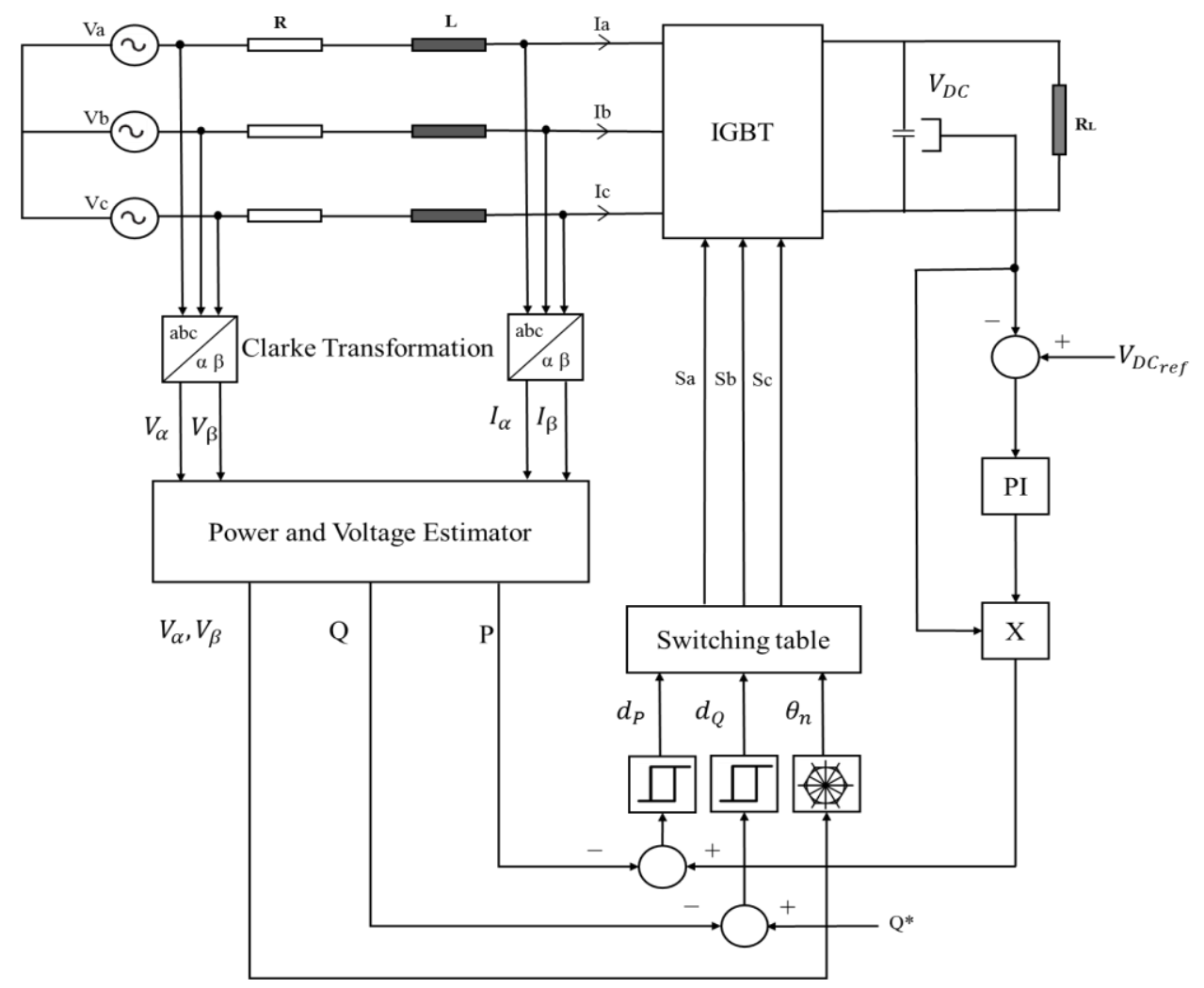

Figure 1. Control structure of direct power control 
Table 1. Switching look-up table for direct power control

\begin{tabular}{llllllllllllll}
\hline Power error status & \multicolumn{10}{c}{ Sector position $\left(\theta_{\mathrm{n}}\right)$ and converter voltage vector $\left(\mathrm{V}_{\mathrm{n}}\right)$} \\
\hline$d_{P}$ & $d_{Q}$ & $\theta_{1}$ & $\theta_{2}$ & $\theta_{3}$ & $\theta_{4}$ & $\theta_{5}$ & $\theta_{6}$ & $\theta_{7}$ & $\theta_{8}$ & $\theta_{9}$ & $\theta_{10}$ & $\theta_{11}$ & $\theta_{12}$ \\
0 & 0 & $\mathrm{~V}_{1}$ & $\mathrm{~V}_{1}$ & $\mathrm{~V}_{2}$ & $\mathrm{~V}_{2}$ & $\mathrm{~V}_{3}$ & $\mathrm{~V}_{3}$ & $\mathrm{~V}_{4}$ & $\mathrm{~V}_{4}$ & $\mathrm{~V}_{5}$ & $\mathrm{~V}_{5}$ & $\mathrm{~V}_{6}$ & $\mathrm{~V}_{6}$ \\
0 & 1 & $\mathrm{~V}_{2}$ & $\mathrm{~V}_{2}$ & $\mathrm{~V}_{3}$ & $\mathrm{~V}_{3}$ & $\mathrm{~V}_{4}$ & $\mathrm{~V}_{4}$ & $\mathrm{~V}_{5}$ & $\mathrm{~V}_{5}$ & $\mathrm{~V}_{6}$ & $\mathrm{~V}_{6}$ & $\mathrm{~V}_{1}$ & $\mathrm{~V}_{1}$ \\
1 & 0 & $\mathrm{~V}_{6}$ & $\mathrm{~V}_{6}$ & $\mathrm{~V}_{1}$ & $\mathrm{~V}_{1}$ & $\mathrm{~V}_{2}$ & $\mathrm{~V}_{2}$ & $\mathrm{~V}_{3}$ & $\mathrm{~V}_{3}$ & $\mathrm{~V}_{4}$ & $\mathrm{~V}_{4}$ & $\mathrm{~V}_{5}$ & $\mathrm{~V}_{5}$ \\
1 & 1 & $\mathrm{~V}_{3}$ & $\mathrm{~V}_{3}$ & $\mathrm{~V}_{4}$ & $\mathrm{~V}_{4}$ & $\mathrm{~V}_{5}$ & $\mathrm{~V}_{5}$ & $\mathrm{~V}_{6}$ & $\mathrm{~V}_{6}$ & $\mathrm{~V}_{1}$ & $\mathrm{~V}_{1}$ & $\mathrm{~V}_{2}$ & $\mathrm{~V}_{2}$ \\
\hline
\end{tabular}

In conventional DPC, a total of four voltage sensors are used to measure the three-phase AC input voltage and DC output voltage, while three current sensors are used to measure the three-phase input currents [12]. Then, the measured currents and voltages are fed into two " $a b c-\alpha \beta$ " blocks which utilize the Clarke Transformation. Both blocks transform the three-phase voltage and current into their corresponding $\alpha \beta$-reference frame. The transformation matrix to the stationary frame is utilized by referring the equation in (1). The three-phase input components are represented by $x_{a}, x_{b}$ and $x_{c}$ while $x_{\alpha}$ and $x_{\beta}$ indicate two-phase components in $\alpha \beta$-reference frame. The angle of supply voltage vector is devided into 12 sector and each sector is $30^{\circ}$ wide as shown in Figure 2.

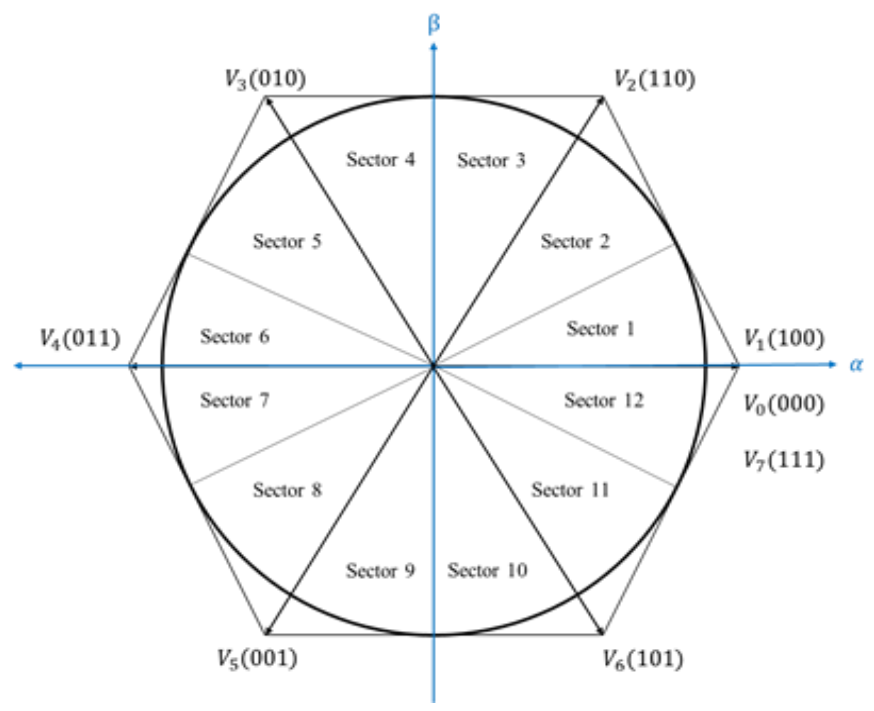

Figure 2. Sector selection for direct power control

The voltage and current in $\alpha \beta$-reference frame are then fed into two blocks to obtain the estimated instantaneous active power $P_{\text {inst }}$, and reactive power $Q_{i n s t}$, as indicated in (2) and (3), respectively. Then, the $P_{\text {inst }}$ and $Q_{i n s t}$ are compared with the reference of active power, $P_{\text {ref }}$ and reactive power, $Q_{\text {ref }}$ values. The error quantities which are denoted by $\Delta P$ and $\Delta Q$, are processed by two hysteresis controllers to obtain active and reactive power errors which is given by $d_{P}$ and $d_{Q}$ respectively. Subsequently, the angle of input voltage vector $\theta_{n}$, is determined by the voltage vector angle converter block regarding to the equation in (6). At that point, the suitable switching states of the converter will be generated by the switching table and the output voltage is kept close to the reference DC voltage by tuning the PI controller appropriately [13, 14].

$$
\begin{gathered}
{\left[\begin{array}{l}
x_{\alpha} \\
x_{\beta}
\end{array}\right]=\frac{2}{3}\left[\begin{array}{ccc}
1 & -\frac{1}{2} & -\frac{1}{2} \\
0 & \frac{\sqrt{3}}{2} & -\frac{\sqrt{3}}{2}
\end{array}\right]} \\
P_{\text {inst }}=\frac{3}{2}\left[V_{\alpha} I_{\alpha}+V_{\beta} I_{\beta}\right] \\
Q_{\text {inst }}=\frac{3}{2}\left[V_{\beta} I_{\alpha}-V_{\alpha} I_{\beta}\right]
\end{gathered}
$$




\subsection{Development of switching table for DPC}

In DPC, the digitized signal $\theta_{n}$ calculate from the phase of voltage vector, which it measured from the three-phase power source using (4). From the equation, the alpha-betha stationary-frame is obtained from the positive sequence.

$$
\theta_{n}=\tan ^{-1}\left(\frac{v_{\beta}^{+}}{v_{\alpha}^{+}}\right)
$$

The switching table in the circuit simulation is creating using "Matlab Function" block. The active power error, $\Delta P$ and reactive power eror, $\Delta Q$ are fed into two hysteresis blocks to obtain the active and reactive power errors status given by $d_{P}$ and $d_{Q}$ respectively.

\section{POWER ANALYSIS UNDER UNBALANCE GRID VOLTAGE}

However, although DPC offer simple control structure and fast dynamic response, it generates high ripples and higher number of Total Harmonic Distortion (THD) during imbalance input voltage $[15,16]$. In order to make the controller to be more robust in such cases, investigations of power converters under unbalanced input voltage conditions are presented in references [17]. The interaction between the harmonic components of the DC output voltage and the converter pole voltages creates even-order harmonics at the DC output and odd-order harmonic components in the input AC current of the PWM AC-DC converter. Consequently, these harmonics components will increase the THD of the AC input current significantly $[18,19]$.

In general, the non-ideal conditions such as unbalanced and distorted three-phase grid voltage supply have negative impacts to the performance and filter size of AC-DC converter system $[20,21]$. Therefore, PWM AC-DC converters under unbalanced operating conditions require the use of input or output filtes of a large size to reduce even and odd-order harmonics at the DC output and AC input supply [22, 23]. Hence, the control techniques of an AC-DC converter need additional investigation to mitigate those negative impacts during voltage unbalance and distorted conditions [24]. For that, it is necessary to split the voltage vector into its sequence components as well as to compute the positive sequence voltage vector angle [25]. Voltage angle calculation is done by means of a PLL while a very simple algorithm is used for sequence extraction.

\subsection{Sequence extractor}

As in introduction part, it was explained that an unbalance input supply has causing negative or zero sequence voltage component as well as a positive sequence voltage component on the grid voltage vector. Therefore, negative sequence component was introduced to the input current in order to adequately compensate for the unbalanced operating condition so that the instantaneous active power becomes constant without oscillating components. The unbalanced detector and symmetyrical component equation that acquires the positive and negative sequence component from three-phase instantaneous quantities such as voltage and current is regarded as an important functional part of the entire unbalance conpensation control system. Hence, positive and negative sequence equations as shown in Table 2 will be applied in this research work in order to generate or extract a negative sequence from the input supply which known as sequence extractor.

Table 2. Sequence extractor equation

\begin{tabular}{ll}
\hline Phase Component & Matrix Equation \\
\hline Zero Sequence & {$\left[\begin{array}{l}V_{a}^{(0)} \\
V_{b}^{(0)} \\
V_{c}^{(0)}\end{array}\right]=\frac{1}{3}\left[\begin{array}{lll}1 & 1 & 1 \\
1 & 1 & 1 \\
1 & 1 & 1\end{array}\right]\left[\begin{array}{c}V_{a} \\
V_{b} \\
V_{c}\end{array}\right]$} \\
Positive Sequence & {$\left[\begin{array}{l}V_{a}^{(+)} \\
V_{b}^{(+)} \\
V_{c}^{(+)}\end{array}\right]=\frac{1}{3}\left[\begin{array}{ccc}1 & a & a^{2} \\
a^{2} & 1 & a \\
a & a^{2} & 1\end{array}\right]\left[\begin{array}{c}V_{a} \\
V_{b} \\
V_{c}\end{array}\right]$} \\
Negative Sequence & {$\left[\begin{array}{l}V_{a}^{(-)} \\
V_{b}^{(-)} \\
V_{c}^{(-)}\end{array}\right]=\frac{1}{3}\left[\begin{array}{ccc}1 & a^{2} & a \\
a & 1 & a^{2} \\
a^{2} & a & 1\end{array}\right]\left[\begin{array}{c}V_{a} \\
V_{b} \\
V_{c}\end{array}\right]$} \\
\hline
\end{tabular}


Where,

$$
a=e^{j 120^{0}}=-\frac{1}{2}+j \frac{\sqrt{3}}{2} \quad \text { and } \quad a^{2}=e^{j 240^{\circ}}=-\frac{1}{2}-j \frac{\sqrt{3}}{2}
$$

Then, in Figure 3 has shown the block diagram for sequence extractor for from three-phase input supplies. From the figure the input suuply has been extracted into three-phase component, which is voltage and current in zero component $\left(V_{a}^{(0)} V_{b}^{(0)} V_{c}^{(0)}\right)\left(I_{a}^{(0)} I_{b}{ }^{(0)} I_{c}{ }^{(0)}\right)$, positive $\left(V_{a}^{(+)} V_{b}^{(+)} V_{c}^{(+)}\right)\left(I_{a}^{(+)} I_{b}{ }^{(+)} I_{c}{ }^{(+)}\right)$component, and negative $\left(V_{a}^{(-)} V_{b}^{(-)} V_{c}^{(-)}\right)\left(I_{a}^{(-)} I_{b}^{(-)} I_{c}^{(-)}\right)$component. The extraction block diagram is creating based on the matric equation as can be seen in Table 2. Next, the phase of input voltage and current from phase sequence are being transformed into alpha-beta stationary-frame. Lastly, the stationary-reference frame from only positive and negative sequence is then fed into another block in order to obtain the estimated instantaneous active power, $P_{\text {out }}$, and reactive power, $Q_{\text {out }}$.

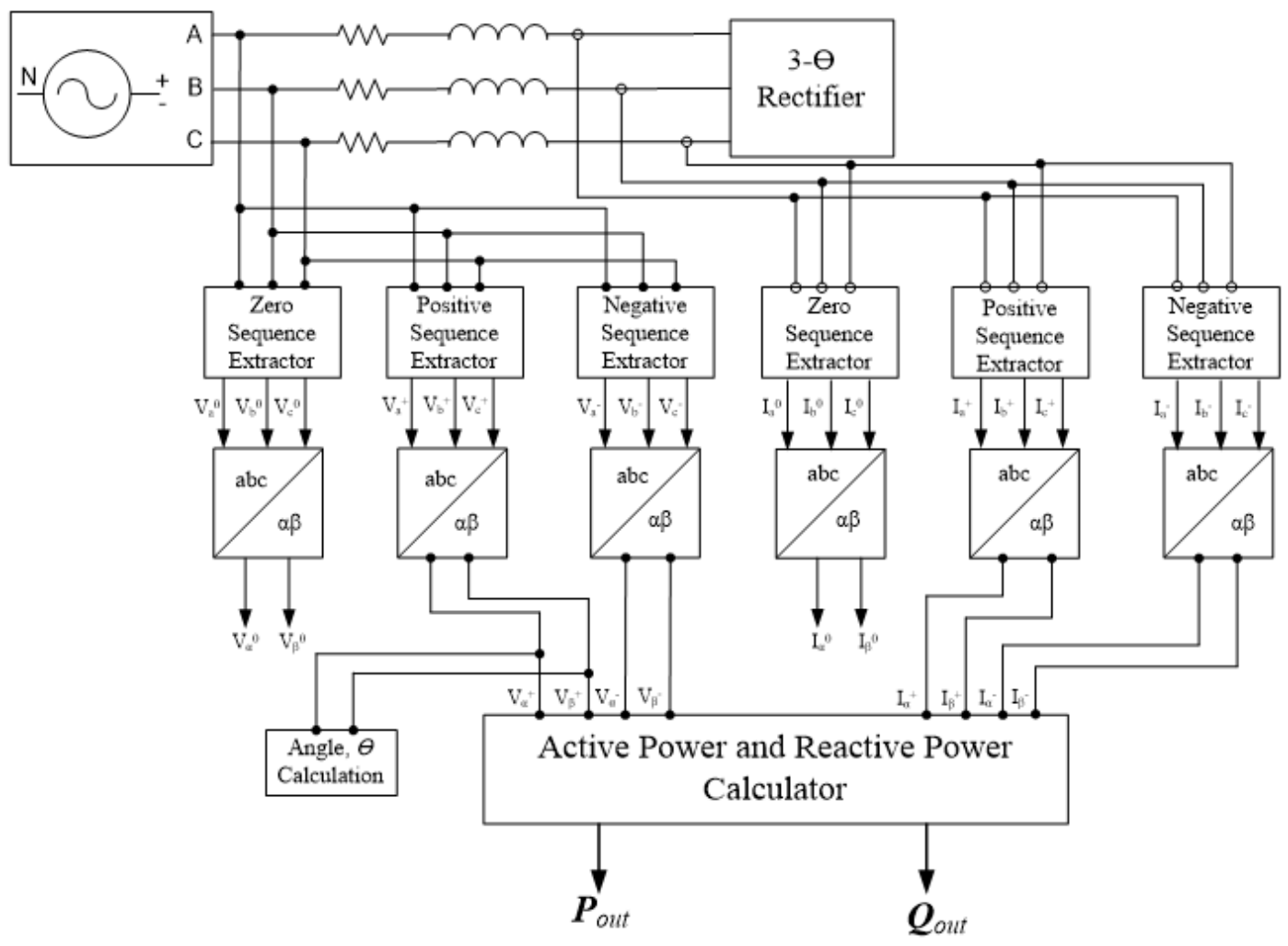

Figure 3. Block diagram for sequence extractor

The instantaneous of the input power $P$ and reactive power $Q$ in a stationary reference frama is given by (5) and (6), respectively.

$$
\begin{aligned}
& p_{\text {out }}(t)=\frac{3}{2}\left(v_{\alpha}^{+} i_{\alpha}^{+}+v_{\beta}^{+} i_{\beta}^{+}+v_{\alpha}^{-} i_{\alpha}^{-}+v_{\beta}^{-} i_{\beta}^{-}+v_{\alpha}^{+} i_{\alpha}^{-}+v_{\beta}^{+} i_{\beta}^{-}+v_{\alpha}^{-} i_{\alpha}^{+}+v_{\beta}^{-} i_{\beta}^{+}+v_{\alpha}^{+} i_{\beta}^{-}-v_{\beta}^{+} i_{\alpha}^{-}+v_{\beta}^{-} i_{\alpha}^{+}-v_{\alpha}^{-} i_{\beta}^{+}\right) \\
& Q_{\text {out }}(t)=\frac{3}{2}\left(v_{\beta}^{+} i_{\alpha}^{+}-v_{\beta}^{+} i_{\beta}^{+}-v_{\beta}^{-} i_{\alpha}^{-}+v_{\alpha}^{-} i_{\beta}^{-}-v_{\alpha}^{+} i_{\beta}^{-}+v_{\beta}^{+} i_{\alpha}^{-}-v_{\beta}^{-} i_{\alpha}^{+}+v_{\alpha}^{-} i_{\beta}^{+}+v_{\alpha}^{+} i_{\alpha}^{-}+v_{\beta}^{+} i_{\beta}^{-}+v_{\alpha}^{-} i_{\alpha}^{+}+v_{\beta}^{-} i_{\beta}^{+}\right)
\end{aligned}
$$

\section{RESULT AND DISCUSSION}

Voltage unbalance is often occurring in supply system [26]. Therefore, the unbalance voltage can be defining as a voltage variation in a power system in which the voltage magnitudes or the phase differences between them are not equal $[27,28]$. Hence, in order to confirm the effectiveness of the additional strategy of sequence extractor into DPC control system, a model of the proposed control strategy for DPC during 
voltage unbalance has been simulated using MATLAB/Simulink. The simulation has been carried out using the main electrical parameter data used in the study is tabulated in Table 3. Several tests were conducted to verify the feasibility and performance of new DPC combining with sequence extractor compared to the conventional one during unbalanced conditions.

Table 3. Main Parameter used in Simulation

\begin{tabular}{ll}
\hline Parameters & Value \\
\hline Input phase voltage (peak), $\mathrm{E}_{\mathrm{g}}$ & $70.71 \mathrm{~V}$ \\
Source Voltage frequency, $\mathrm{f}$ & $50 \mathrm{~Hz}$ \\
Dc-link volatage reference, $\mathrm{V}_{\mathrm{dc}, \text { ref }}$ & $200 \mathrm{~V}$ \\
Resistance of reactance, $\mathrm{R}$ & $0.2 \Omega$ \\
Inductance of reactance, $\mathrm{L}$ & $18 \mathrm{mH}$ \\
Dc-link capacitor, C & $10.8 \mathrm{mF}$ \\
Load Resistance, $\mathrm{R}_{\mathrm{L}}$ & $140 \Omega$ \\
Sampling time, $\mathrm{t}_{\mathrm{s}}$ & $20 \mu \mathrm{s}$ \\
\hline
\end{tabular}

Simulation result of the three-phase PWM rectifier operation for unbalanced input voltage under conventional DPC is shown in Figure 4 below. In this case, the unbalance voltage supply can be seen into phase a where the amplitude had been pre-set $50 \%$ from input phase peak voltage, $70.71 \mathrm{~V}$ as shown in Figure 4(a) [29]. Thus, the reducing amount of voltage has resulting the value of current on phase a into an excessive amount as shown in Figure 4(b), which the current for Ia is greater compared than other phases. Consequently, it resulting for a higher number of Total Harmonic Distortion (THD=22.7\%) as shown in current spectrum in 4(c). It proves that, the input current in unbalance condition is highly distorted.

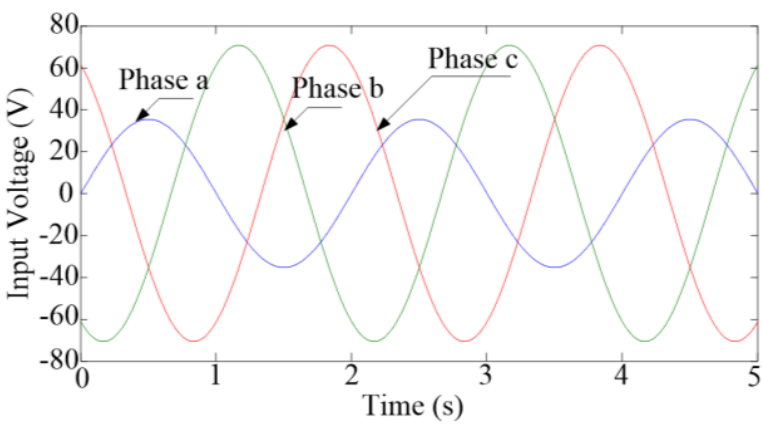

(a)

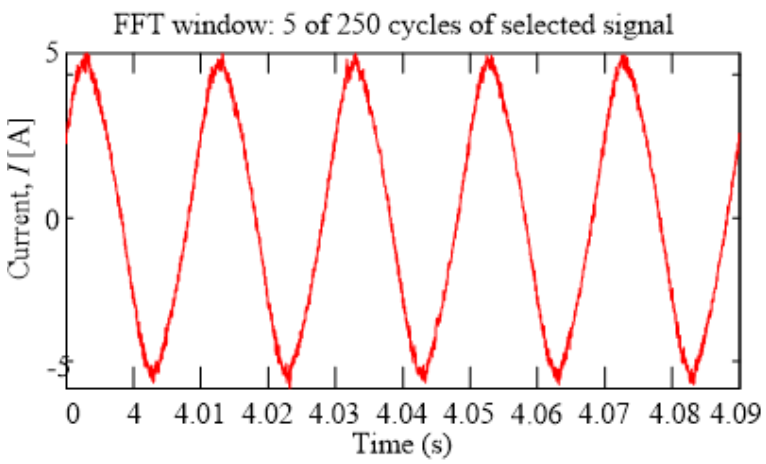

(c)

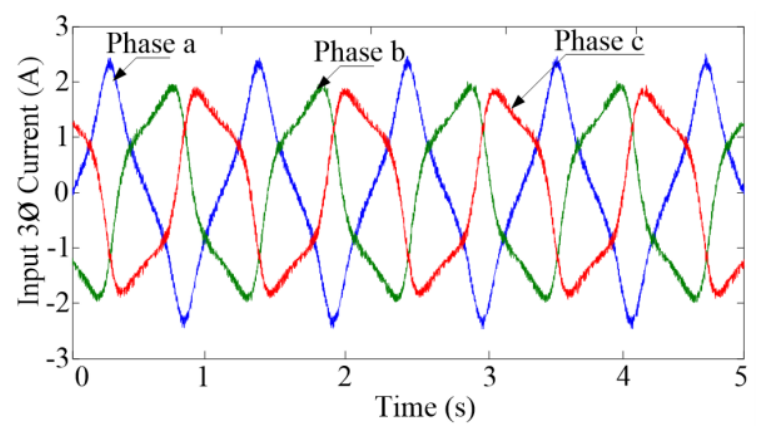

(b)

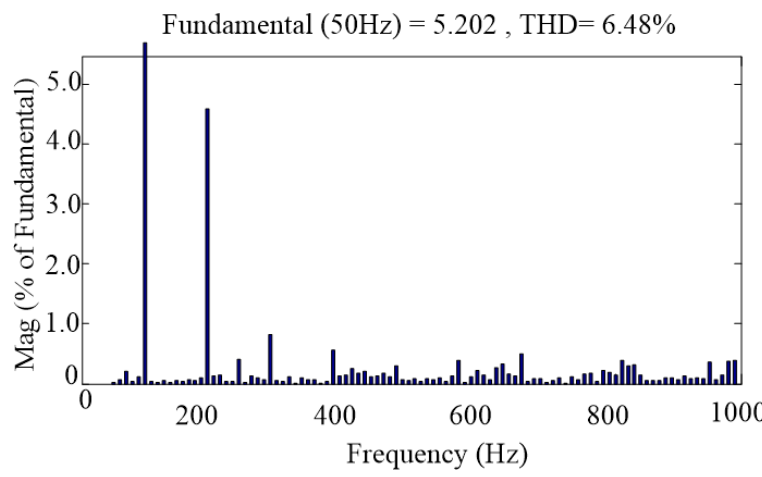

)

Figure 4. Simulation result for conventional DPC of PWM AC-DC Converter under unbalanced input voltage (a) Input voltage, (b) Input current, (c) FFT Analysis on phase $a$

Then, in Figure 5 has shown the entire results of the three-phase PWM rectifier operation under additional of sequence extractor method into DPC. It verifies that this method is capable to improve the current waveforms nearly too almost sinusoidal waveform as shown in 5(a) [30]. Accordingly, it resulting for a lower number of Total Harmonic Distortion (THD=6.48\%) in 5(b) and $P$ and $Q$ waveform in 4(c). 
Then, the output of DC voltage is obtained in 5(d) and it can be seen that there is an increment in rising time and settling time before the output voltage reaches the steady state. This is due to the tuning of $P I$ controller which involves increasing value of $K p$ and $K i$.

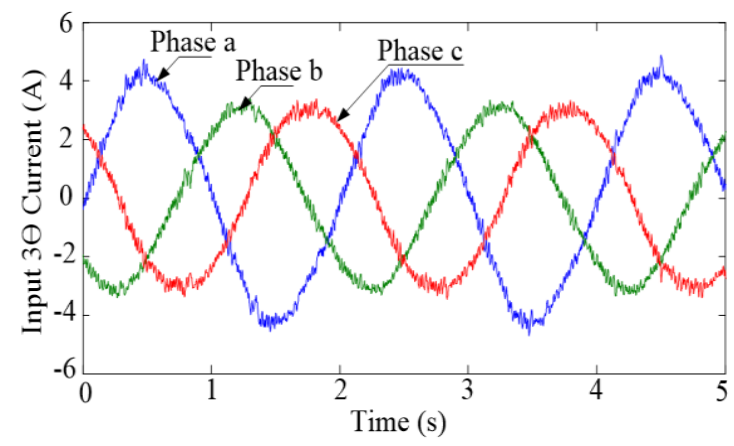

(a)
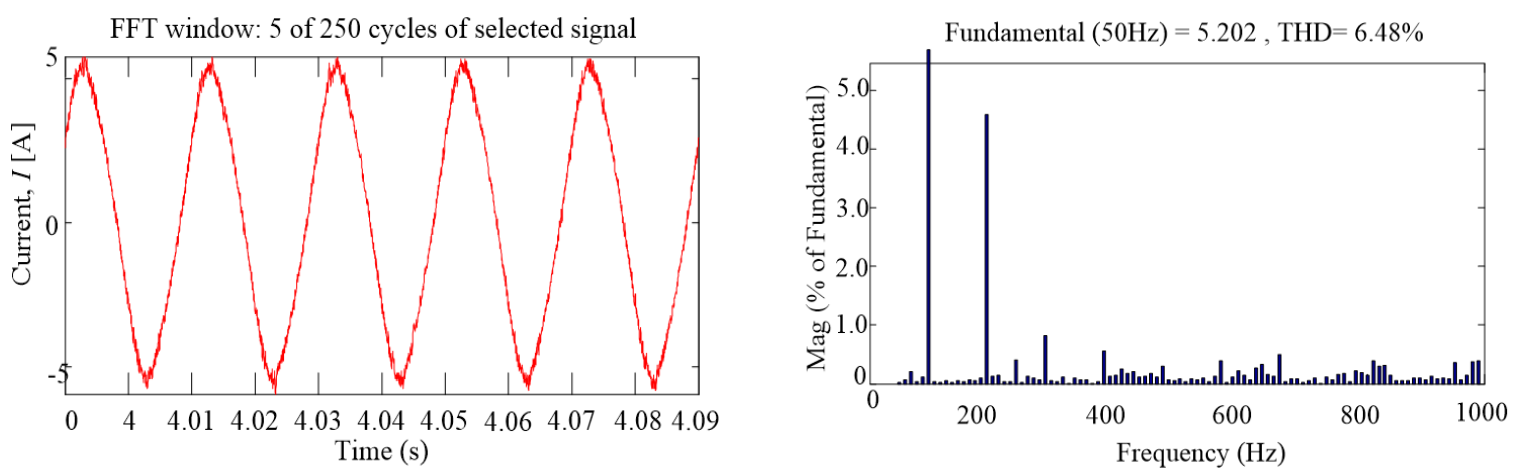

(b)

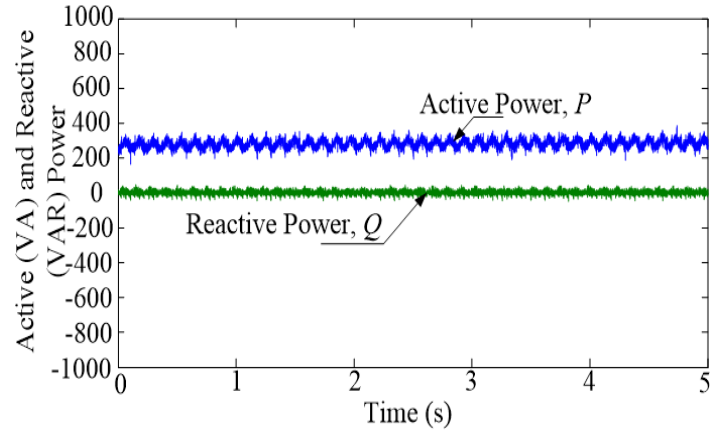

(c)

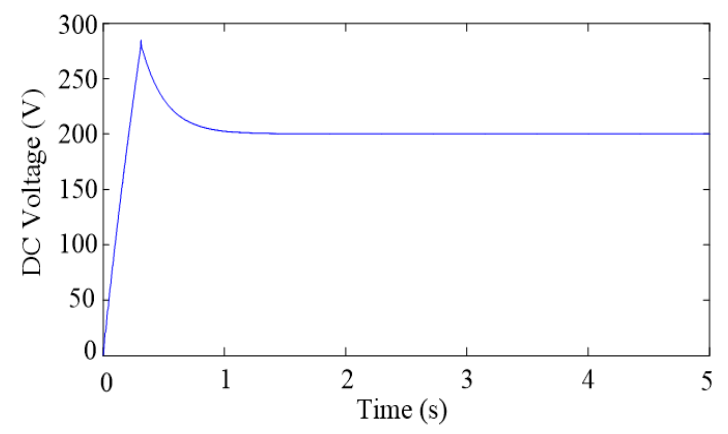

(d)

Figure 5. Simulation results for additional of sequence extractor into DPC of PWM AC-DC Converter under unbalanced input voltage, (a) Input current, (b) Harmonic spectrum on phase $a$,

(c) Active and reactive power, (d) DC voltage

Figure 6(a) shows transient response when the DC voltage reference changes from $150 \mathrm{~V}$ to $180 \mathrm{~V}$ and back to $150 \mathrm{~V}$ at $3 \mathrm{~s}$ while $6(\mathrm{~b})$ from $150 \mathrm{~V}$ to $120 \mathrm{~V}$ and back to $150 \mathrm{~V}$. With the estimated quantities of the dc-link voltage $P I$ regulator, the control performance is satisfactory. Figure 7 shows transient response during load variation. The load variation is performed by connecting abruptly a $100 \Omega$ resistor in parallel with the existing resistor across the dc-link at the time of $3 \mathrm{~s}$, to cause a sudden disturbance in the load current. The line current and estimated active power, immediately follow the change on the active power reference. The response occurs very quickly without any undesirable overshoot and oscillation. Forced by the voltage PI regulator, the dc output voltage recovers to the original value of $150 \mathrm{~V}$ after experiencing a small dip. 


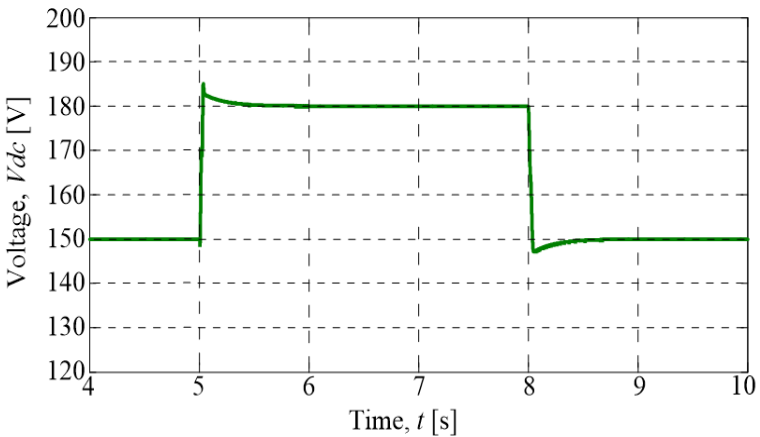

(a)

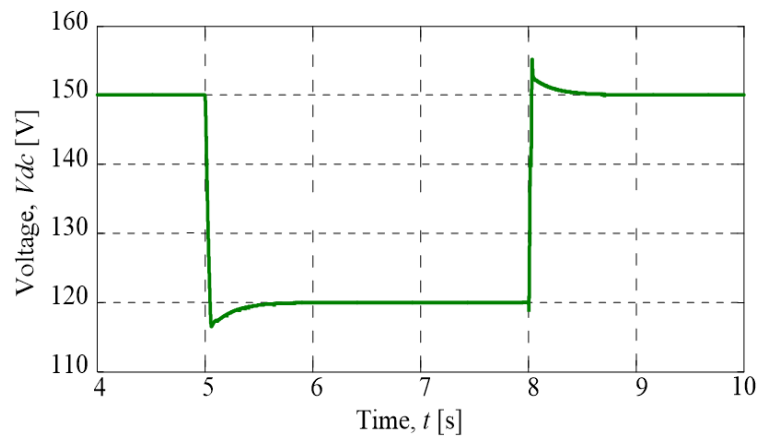

(b)

Figure 6. Transient response for the step changes of DC-link voltage, (a) $150 \mathrm{~V}$ to $180 \mathrm{~V}$, (b) $150 \mathrm{~V}$ to $120 \mathrm{~V}$

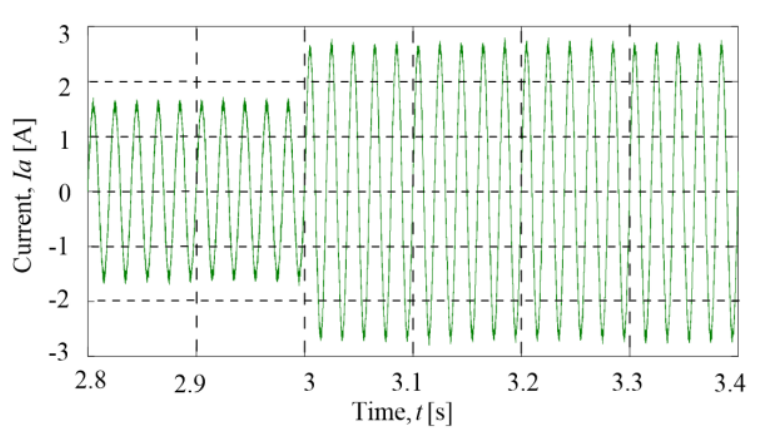

(a)

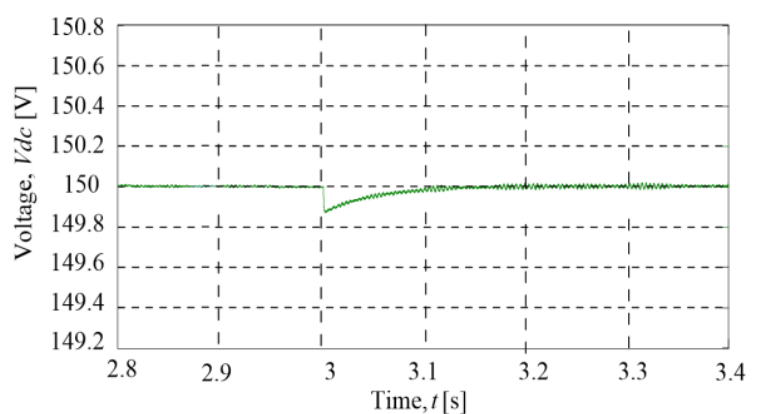

(b)

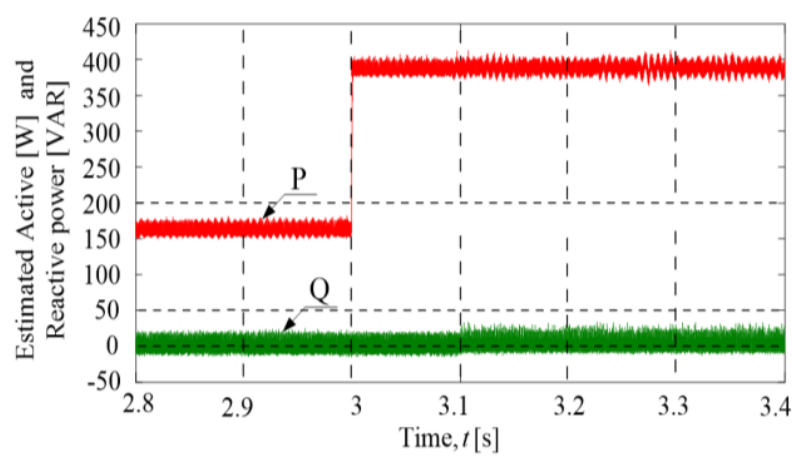

(c)

Figure 7. Transient response for load variation from low to high current demand; (a) Phase $a$,

(b) DC-link voltage, (c) Estimated active and reactive power

\section{CONCLUSION}

This paper has presented the implementation of a sequence extractor into Direct Power Control scheme. The main goal for the additional strategy of sequence extractor is to achieve for near-sinusoidal input current waveform of the converter under different amplitude input voltage conditions. In-fact, instantaneous active and reactive powers provided by harmonic component of input current are directly controlled via a switching table. Simulation result has proven excellent performance of the proposed additional strategy of sequence extractor, which is much better than conventional DPC by reducing almost for $70 \%$ of Total Harmonic Distortion (THD), even in both transient and steady states conditions. Nearly sinusoidal waveform of input current is successfully achieved under unbalance input voltage conditions. The presented simulation results confirm that the additional of sequence extractor into DPC is capable to ensure the correcting unbalance of input voltage, unlike the conventional DPC is resulting for decreasing percentage of productive current, thus it providing for high number of THD current. Then, in study for the dynamic performance for the variation in load and DC voltage reference, it is observed that the output 
voltage recovers close to the reference voltage despite the sudden disturbance introduced to the system. The proper tuning of PI controller enables the output voltage remains near to reference voltage. Meanwhile, the active power increases significantly when a smaller resistance value is connected parallel with existing circuit which reduces the overall load.

\section{ACKNOWLEDGMENT}

The authors would like to thank 'Skim Zamalah' from Universiti Teknikal Malaysia Melaka (UTeM) as providing for continuous financial support that enabled the achievement of this research result and research incentive grant (Jurnal/2019/FKE/Q00016).

\section{REFERENCES}

[1] Wang Feng and Luo Yutao, "Modelling of a Power Converter with Multiple Operating Modes," World Electric Vehicle Journal, pp. 1-17, 2018.

[2] K. Venkateshvarlu and Ch. Chengaiah, "Comparative Study on DC Motor Speed Control using Various Controllers," Global Journal of Researchers in Engineering Electrical and Electronics Engineering, vol. 13, no. $17,2013$.

[3] Bhim Singh, Brij N. Singh, Ambrish Chandra, Kamal Al-Hadad, Ashish Pandey, and Dwarka P. Kothari, "A Review of Three-Phase Improved Power Quality AC - DC Converters," IEEE Transactions on Industrial Electronics, vol. 51(3), pp. 641-660, June 2004.

[4] Y. Zhang, J. Jiao, J. Liu, and J. Gao, "Direct power control of PWM rectifier with feedforward compensation of DC-bus voltage ripple under unbalanced grid conditions," IEEE Transaction Ind.ustrial Application., vol. 55, no. 3 , pp. 2890-2901, May 2019.

[5] D. Sun, X. Wang, and Y. Fang, "Backstepping Direct Power Control Without Phase-Locked Loop Of AC/DC Converter Under Both Balanced And Unbalanced Grid Conditions," IET Power Electronic, vol. 9, no. 8, pp. 1614-1624, 2016.

[6] Dawei Zhi, Lie Xu, and Barry W. Williams, "Improved Direct Power Control of Grid-Connected DC/AC Converter," IEEE Transaction Power Electronic, vol. 24, no. 5, 2009.

[7] Y. Quan, N. Heng and H. Jiabing, Improved Control of the Grid-connected Converter under the Harmonically Distorted Grid Voltage Conditions", IEEE International Conference. pp. 204-209, 2010.

[8] A. M. Razali, M.A. Rahman, and Glyn George, "An Analysis of Direct Power control for Three Phase AC-DC Converter," Industry Applications Society Annual Meeting (IAS), pp. 1-7, 2012.

[9] Nor Azizah Mohd Yusoff, Azziddin Muhammad Razali, Kasrul Abdul Karim, Loong Jie Yan, "A Direct Power Control of AC/DC Converter," Journal of Engineering Sciences and Techonology, pp. 13-21, Feb. 2019.

[10] Nor Azizah Mohd Yusoff, Azziddin Muhammad Razali, Kasrul Abdul Karim, Tole Sutikno, and Auzani Jidin, "A Concept of Virtual-FluxDirect Power Control of AC-DC Converter," International Journal of Power Electronics and Drive System (IJPEDS), vol. 8, no. 4, pp. 1176-1784, Dec 2017.

[11] Zhang, Y., Li, Z., Zhang, Y., Xie, W., Piao, Z., and Hu, C., "Performance Improvement of Direct Power Control of PWM Rectifier with Simple Calculation," IEEE Transactions on Power Electronics, vol. 28, no. 7, pp. 3428-3437, 2013.

[12] Jingjing Huang, Fanghong Guo, Changyun Wen, Bo Yang and Jianfang Xiao, “A Direct Power Control Strategy on Best Switching State Approach,” IEEE Transaction Power Electronic, vol. 6, no. 4, 2018.

[13] J. Hu, J. Zhu, and D.G. Dorrell, "In-Depth Study of Direct Power Control Strategies For Power Converters," IET Power Electron, vol. 7, no. 7, pp. 1810-1820, 2014.

[14] A. M. Razali, M.A. Rahman, "Performance Analysis of Three-Phase PWM Rectifier Using Direct Power Control," in International Electric Machines and Drives Conference(IEMDC), pp. 1603-1608, 2011.

[15] Tapan, "A Review on Direct Power Control for Applications to Grid Connected PWM Converters," Engineering Technology and Applied Science Research, vol. 5, no. 4, pp. 841-849, 2015.

[16] Y. Zhang, J. Jiao, and J. Liu, "Direct power control of PWM rectifiers with online inductance identification under unbalanced and distorted network conditions, " IEEE Trans. Power Electron., vol. 34, no. 12, pp. 12 524-12 537, Dec. 2019.

[17] Nian, H., Shen, Y., Yang, H., and Quan, Y., "Flexible Grid Connection Technique of Voltage-Source Inverter under Unbalanced Grid Conditions Based on Direct Power Control," IEEE Transactions on Industry Applications, vol. 51, no. 5, pp. 4041-4050, 2015.

[18] Suh, Y., and Lipo, T. A., "Modeling and Analysis of Instantaneous Active and Reactive Power for PWM AC/DC Converter under Generalized Unbalanced Network," IEEE Transactions on Power Delivery, vol. 21, no. 3, pp. 1530-1540, 2006.

[19] Xiao, P., Corzine, K.A., and Venayagamoorthy, G.K., "Multiple Reference Frame-Based Control of Three-Phase PWM Boost Rectifiers under Unbalanced and Distorted Input Conditions," IEEE Transactions on Power Electronics, vol. 23, no. 4, pp. 2006-2017, 2008.

[20] Nian, H., Song, Y., Zhou, P., and He, Y., "Improved Direct Power Control of a Wind Turbine Driven Doubly Fed Induction Generator during Transient Grid Voltage Unbalance," IEEE Transactions on Energy Conversion, vol. 26, no. 3, pp. 976-986, 2011. 
[21] Zhang, Y., and Qu, C., "Model Predictive Direct Power Control of PWM Rectifiers under Unbalanced Network Conditions," IEEE Transactions on Industrial Electronics, vol. 62, no. 7, pp. 4011-4022, 2015.

[22] Imad Merzouk and Mohamed Lomane Bendaas, "Improved Direct Power Control for 3-Level AC/DC Converter under Unbalanced and/or Distorted Voltage Source Conditions," Turkish Journal of Electrical Engineering \& Computer Sciences, vol. 24, pp. 1847-1862, 2016.

[23] Merzouk I, Bendaas ML, Gaafazi A, and Rizaoui M., "Improved Direct Power Control for three-level AC/DC converter under unbalanced voltage source conditions," $1^{\text {ST }}$ International Conference on Power Electronics and Their Application, Nov 2013.

[24] Yongchang Zhang, Zeting Wang, Jian Jiao, and Jie Liu, "Grid-voltage Sensorless Model Predictive Control of Three-Phase PWM Rectifier under Unbalanced and Distorted Grid Voltages" IEEE Transaction in Power Electronic, 2019.

[25] F.Bradaschia, J.P. Arruda, H. E. P. Souza, G. M. S. Azevedo, F. A. S. Neves, and M. C. Cavalcanti, "A Method for Extracting the Fundamental Frequency Positive-Sequence Voltage Vector Based on Simple Mathematical Transformations," IEEE Power Electronics Specialist Conference, vol. 1, pp. 1115-1121, June 2008.

[26] B.Kahia, A. Bouafia, and A. Chaoui, "Direct Power Control of Three-Level PWM Rectifier under Unbalanced and harmonically Distorted Grid Voltage Conditions," IEEE Transaction Power Electronic, 2015.

[27] M. Malinowski, G. Marques, M. Cichowlas, and M. P. Kazmierkowski, "New direct power control of three-phase pwm boost rectifiers under distorted and imbalanced line voltage conditions," IEEE International Symposium on Industrial Electronics, pp. 438-443, June 2003.

[28] H. Yang, Y. Zhang, J. Liang, J. Gao, P. D. Walker, and N. Zhang, "Sliding-Mode Observer Based VoltageSensorless Model Predictive Power Control of PWM Rectifier Under Unbalanced Grid Conditions," IEEE Trans. Ind. Electron, vol. 65, no. 7, pp. 5550-5560, Jul 2018.

[29] Nor Azizah Mohd Yusoff, Azziddin Muhammad Razali, Kasrul Abdul Karim, Tole Sutikno, and Auzani Jidin, "An Analysis of Virtual-FluxDirect Power Control of AC-DC Converter," International Journal of Power Electronics and Drive System (IJPEDS), vol. 9, no. 3, pp. 947-956, Sep 2018.

[30] Nor Azizah Mohd Yusoff, Azziddin Muhammad Razali, Kasrul Abdul Karim, and Auzani Jidin, "The Direct Power Control of AC-DC Converter under Unbalance Voltage Condition," International Journal of Electrical and Computer Engineering (IJECE), vol. 9, no. 6, pp. 5107-5114, Dec 2019. 